\title{
Aminopropyl-silica supported Cu nanoparticles: an efficient catalyst for continuous-flow Huisgen azide-alkyne cycloaddition (CuAAC)
}

Ravindra P. Jumde, ${ }^{\mathrm{a}}$ Claudio Evangelisti, ${ }^{\mathrm{a},{ }^{*}}$ Alessandro Mandoli, ${ }^{\mathrm{a}, \mathrm{b}}$ Nicola Scotti, ${ }^{\mathrm{a}}$ and Rinaldo Psaro $^{\mathrm{a}, *}$

${ }^{a}$ CNR, Institute of Molecular Science and Technologies (ISTM), Via G. Fantoli 16/15, 20138 Milan, Italy; ${ }^{b}$ Department of Chemistry and Industrial Chemistry, University of Pisa, Via G. Moruzzi 3, 56124 Pisa, Italy,

\begin{abstract}
$\mathrm{Cu}$ nanoparticles prepared by metal vapor synthesis (MVS) were immobilized on 3-aminopropyl functionalized silica at room temperature. HRTEM analysis of the catalyst showed that the copper nanoparticles are present with mean diameters limited in the range $1.0-4.5 \mathrm{~nm}$. TPR analysis were performed in order to study the oxidation state of the supported copper nanoparticles. The supported catalyst was used both in batch and in a packed-bed reactor for continuous-flow $\mathrm{CuAAC}$ reaction. The activation of the copper catalyst by reduction using phenyl hydrazine in continuous flow conditions was demonstrated. Along with the high catalytic activity (productivity up to 1689 $\mathrm{mol} / \mathrm{mol}$ ), the catalyst can be used several times with negligible $\mathrm{Cu}$ leaching in the product $(<9$ ppm), less than allowed $\mathrm{Cu}$ contaminant in pharmaceuticals. The applicability of packed-bed flow reactor was showed by sequentially converting different substrates in their corresponding products using same column.
\end{abstract}

\section{Keywords:}

Catalysed Azide-alkyne cycloaddition, supported copper nanoparticles, flow-chemistry, metal vapor synthesis

Corresponding Authors: Claudio Evangelisti, Rinaldo Psaro

E-mail addresses: claudio.evangelisti@istm.cnr.it; rinaldo.psaro@istm.cnr.it 


\section{Introduction}

The regioselective $\mathrm{Cu}(\mathrm{I})$ catalyzed 1,3-dipolar azide-alkyne cycloaddition leading to 1,4disubstituted-1,2,3-triazoles (CuAAC) was independently introduced by the groups of Meldal and Sharpless.[1-3] Since then, the broad applicability, ease reliability and high efficiency of this reaction stimulated an increasing interest for a wide range of synthetic applications, from drug discovery to material science and chemical biology.[4-12] Different copper sources have been described for the CuAAC, including simple halide salts and coordination complexes in homogeneous or heterogeneous form.[13-22] From the last decade nanostructured $\mathrm{Cu}$ systems are being explored in both homogeneous and heterogeneous form in CuAAC reactions.[13,14,23-30] The combination of supported $\mathrm{Cu}$-based catalysts and flow reactor technologies represent a step forward in terms of reliability, time, safety, and costs over traditional batch reaction conditions. Recently, considerable efforts in this direction have been devoted to the preparation of innovative $\mathrm{Cu}$-based catalysts by using different strategies to perform CuAAC in flow.[31-38] However, the development of highly recyclable heterogeneous systems with a copper contamination content into the final product at the acceptable levels, still remains a challenge.[35]

Here we report the preparation of $\mathrm{Cu}$ nanoparticles supported on 3-aminopropyl functionalized silica $\left(\mathrm{APSiO}_{2}\right)$ by metal vapor synthesis (MVS) technique and their use as catalyst both in batch and in continuous-flow Huisgen azide-alkyne cycloaddition (CuAAC). Supported $\mathrm{Cu}$ catalyst showed remarkable activity and stability in continuous-flow $\mathrm{CuAAC}$ with a very low $\mathrm{Cu}$ leaching in the product. In addition, the activation and re-generation of the catalyst by flowing phenyl hydrazine as a reducing agent for copper, was demonstrated. In order to better understand the morphology and the active phase of the supported copper nanoparticles, high resolution electron microscopy and temperature programmed reduction (TPR) analysis, both in the pristine state and after use in catalysis, were performed.

\section{Experimental}




\subsection{General}

All the reactions involving sensitive compounds were carried out under dry argon by using conventional Schlenk technique. All anhydrous solvents were either purchased in Sure/Seal ${ }^{\mathrm{TM}}$ bottles or dried by standard procedure. $\mathrm{Cu}$ shots, $2-8 \mathrm{~mm}, 99.999 \%$ trace metals basis, were purchased from Strem Chemicals. Acetone (Aldrich product) was dried over molecular sieves and stored under dry argon. 3-Aminopropyl functionalized silica gel (40 - $63 \mu \mathrm{m}$, extent of labelling: $~ 1$ $\mathrm{mmol} / \mathrm{g} \mathrm{NH}_{2}$ was purchased from Silicycle. If not noted otherwise, the other compounds were used as received. TLC analyses were carried out with Macherey-Nagel ALOX-25 UV254 plates (0.25 $\mathrm{mm}$ ) and chromatography purifications with Merck 9385 flash grade silica-gel (230-400 mesh). Unless noted otherwise, ${ }^{1} \mathrm{H}$ and ${ }^{13} \mathrm{C}$ NMR spectra were recorded as $\mathrm{CDCl}_{3}$ solutions on a Varian INOVA-600 spectrometer operating at $600 \mathrm{MHz}$ and $150 \mathrm{MHz}$ for ${ }^{1} \mathrm{H}$ and ${ }^{13} \mathrm{C}$, respectively. Chemical shifts are reported in ppm relative to TMS $\left({ }^{1} \mathrm{H}\right)$ or to the solvent $\left({ }^{13} \mathrm{C}, \mathrm{CDCl}_{3}\right.$ at 77.16 ppm). Data are summarized as follows: chemical shift, multiplicity $(\mathrm{s}=$ singlet, $\mathrm{d}=$ doublet, $\mathrm{t}=$ triplet, $\mathrm{q}=$ quartet, $\mathrm{m}=$ multiplet, $\mathrm{dd}=$ doublet of doublets, $\mathrm{ddd}=$ doublet of doublet of doublets, $\mathrm{dt}$ $=$ doublet of triplets, $\mathrm{td}=$ triplet of doublets and $\mathrm{br}=$ broad $)$, coupling constants, and integration . Electrospray mass analyses were carried out in the positive [MS(ESI+)] or negative [MS(ESI-)] ion mode on methanolic solutions, with a Perkin-Elmer-Sciex Api 3000 spectrometer. Inductively Coupled Plasma-Optical Emission Spectrometer (ICP-OES; iCAP 6200 Duo upgrade, Thermofisher). For ICP-OES, a sample (1 mL) of solution was heated over a heating plate in a porcelain crucible in the presence of aqua regia $(2 \mathrm{~mL})$ for four times, dissolving the solid residue in 0.5 M aqueous $\mathrm{HCl}$. The limit of detection (lod) calculated for copper was $0.01 \mathrm{ppm}$. Electron micrographs were obtained with a Zeiss LIBRA 200FE, equipped with: $200 \mathrm{kV}$ FEG, in column second-generation omega filter for energy selective spectroscopy (EELS) and imaging (ESI), HAADF STEM facility, EDS probe for chemical analysis, integrated tomographic HW and SW. Before introduction in the instrument, the samples were ultrasonically dispersed in isopropyl alcohol and a drop of the suspension was deposited on a holey carbon gold grid (300 mesh). The 
histograms of the metal particle size distribution for the $\mathrm{Cu}$ samples were obtained by counting at least 500 particles onto the micrographs. The mean particle diameter $\left(\mathrm{d}_{\mathrm{m}}\right)$ was calculated by using the formula $d_{m}=\sum d_{i} n_{i} / \sum n_{i}$, where $n_{i}$ is the number of particles with diameter $d_{i}$. Temperature Programmed Reductions (TPR) profiles were recorded with a modified version of the Micromeritics Pulse Chemisorb 2700 apparatus. The catalysts $(50 \mathrm{mg})$ were diluted with quartz, pre-treated under Ar at $150{ }^{\circ} \mathrm{C}$ and reduced at $8{ }^{\circ} \mathrm{C} / \mathrm{min}$ with a $8 \% \mathrm{H}_{2} / \mathrm{Ar}$ mixture at $15 \mathrm{~mL} / \mathrm{min}$.

\subsection{Preparation of $\mathrm{Cu}$ nanoparticles supported on 3-aminopropyl-silica $\left(\mathrm{Cu} / \mathrm{APSiO}_{2}\right)$}

The synthesis of $\mathrm{Cu} /$ acetone solvated metal atoms (SMA) was carried out in a static MVS reactor, similar to those previously described.[39,40] In a typical experiment, copper vapors, generated by resistive heating of an tungsten-alumina crucible filled with ca. $500 \mathrm{mg}$ of copper shots, were cocondensed at liquid nitrogen temperature with acetone $(100 \mathrm{~mL})$ in the glass reactor chamber of the MVS apparatus in ca. 2 hours $\left(\mathrm{P}=5 \times 10^{-4} \mathrm{mBar}\right)$. The reactor chamber was warmed to the melting point of the solid matrix (ca.-80 ${ }^{\circ} \mathrm{C}$ ) and the resulting brown solution was siphoned at low temperature in a Schlenk tube and kept in a refrigerator at $-40^{\circ} \mathrm{C}$. The content of the copper in SMA was $0.4 \mathrm{mg} / \mathrm{mL}$, as determined ICP-OES analysis. A portion of $50 \mathrm{~mL}(20 \mathrm{mg}$ of $\mathrm{Cu}$ ) was added to a suspension of 3-aminopropyl functionalized silica support (2 g, previously degased for three times at $25^{\circ} \mathrm{C}$ and kept under dry argon atmosphere) in acetone $(20 \mathrm{~mL})$. The mixture was stirred for $12 \mathrm{~h}$ at room temperature. The colourless solution was removed and the light-brown solid, containing 1 wt. \% of $\mathrm{Cu}$, was washed 3 times with n-pentane $(20 \mathrm{~mL})$ and dried under reduced pressure. The same procedure was used to prepare $\mathrm{Cu} / \mathrm{APSiO}_{2}$ system containing 0.55 wt.\% of $\mathrm{Cu}$. The catalysts were stored under dry argon atmosphere by using standard Schlenk techniques.

\subsection{CuAAC reaction in batch conditions: general procedure}


A 25-mL Schlenk tube fitted with a glass frit and stopcock side arm, was charged under argon with $\mathrm{Cu} / \mathrm{APSiO}_{2}(65 \mathrm{mg}, 1 \mathrm{wt} . \%$ of $\mathrm{Cu}, 0.01 \mathrm{mmol}, 0.02$ equiv. $)$, and dry THF (2 mL), followed by benzyl azide $(62.5 \mu \mathrm{L}, 0.5 \mathrm{mmol}, 1$ equiv.) and phenyl acetylene $(65.9 \mu \mathrm{L}, 0.6$ mmol, 1.2 equiv.). The flask was closed under argon and kept stirring at $25^{\circ} \mathrm{C}$, for the time $\mathrm{t}$ (Table 1). Then the mixture was filtered through the enclosed frit, collecting the filtrate and catalyst rinses with THF $(2 \times 2 \mathrm{~mL})$. For the regeneration, the catalyst was treated with the solution of $\mathrm{PhNHNH}_{2}(34 \mu \mathrm{L}, 0.35 \mathrm{mmol})$ in $\mathrm{THF}(5 \mathrm{~mL})$ for $15 \mathrm{~h}$ at room temperature. Then catalyst was washed with THF $(2 \times 5 \mathrm{~mL})$, dried under argon flow and used in next run.

\subsection{Control experiments for catalytic activity in solution.}

Each of two $25 \mathrm{~mL}$ Schlenk tubes (A and B) fitted with a medium porosity glass frit and stopcock side arm, was charged under argon with $\mathrm{Cu} / \mathrm{APSiO}_{2}(65 \mathrm{mg}, 1 \mathrm{wt} . \%$ of $\mathrm{Cu}, 0.01 \mathrm{mmol}, 0.02$ equiv.). The catalyst in Schlenk-A was pre-activated with $\mathrm{PhNHNH}_{2}(9.8 \mu \mathrm{L}, 0.1 \mathrm{mmol})$, washed with THF, and dried as above, while the catalyst in Schlenk-B was used in its pristine form. Each tube was charged with THF $(2 \mathrm{~mL})$, benzyl azide $(0.5 \mathrm{mmol}, 1$ equiv. $)$ and phenyl acetylene $(0.6$ mmol, 1.2 equiv.), sealed under argon and kept stirring at $25^{\circ} \mathrm{C}$, for $2 \mathrm{~h}$. Then the mixtures were filtered through the enclosed frit under argon into another Schlenk tube. NMR analysis of small amount of mixture from Schlenk-A and Schlenk-B at this stage showed 50 and $35 \%$ conversion, respectively. Keeping reaction mixture at $25^{\circ} \mathrm{C}$ under argon for additional $4 \mathrm{~h}$ showed only slight increase in conversion of benzyl azide to 1,2,3-triazol product (See Figure 2S).

\subsection{Preparation of $\mathrm{Cu} / \mathrm{APSiO}_{2}$ packed-bed reactor}

Packed-bed reactor was prepared in a commercially available PTFE tubing with Luer-lock fitting (Figure. $1 \mathrm{~S}, 161 \times 1 \mathrm{~mm}$ i.d.). As shown in Fig. 1, glass wool and a piece of smaller PTFE tube (o.d. 1/16") were used as a frit at the tubing end devoid of the Luer-lock fitting. Catalyst was packed by sucking $\mathrm{Cu} / \mathrm{APSiO}_{2}$ from Schlenk tube with the help of vacuum. In 
order to keep the catalyst bed in place, glass wool and a short piece of 1/16" o.d. PTFE tubing was also placed at the other end of the reactor.

\subsection{CuAAC reaction under continuous-flow conditions: general procedure}

The Luer-lock PTFE tubing packed with $\mathrm{Cu} / \mathrm{APSiO}_{2}\left(190 \mathrm{mg} \mathrm{Cu} / \mathrm{APSiO}_{2}, 1\right.$ wt.\% or $230 \mathrm{mg}$ $0.55 \mathrm{wt} \% \mathrm{Cu}$ loading, respectively) was connected to a $5 \mathrm{~mL}$ SGE Gas-Tight syringe and flushed with dry THF for $30 \mathrm{~min}$ at $50 \mu \mathrm{L} \cdot \mathrm{min}^{-1}$ flow rate. The CuAAC reaction was then carried out at $25^{\circ} \mathrm{C}$, by flushing the solution of reagents (benzyl azide (1), $3.75 \mathrm{mmol}, 1$ equiv.; phenyl acetylene (2), $4.5 \mathrm{mmol}, 1.2$ equiv.; solvent $=\mathrm{THF}, 15 \mathrm{~mL}$ ) through the reactor at $50 \mu \mathrm{L} \cdot \mathrm{min}^{-1}$ flow rate. For regeneration, the reactor was flushed with $\mathrm{PhNHNH}_{2}$ $(103 \mu \mathrm{L}, 1.05 \mathrm{mmol})$ in $\mathrm{THF}(5 \mathrm{~mL})$ at $50 \mu \mathrm{L} \cdot \mathrm{min}^{-1}$ flow rate. For the runs carried out in presence of reducing agent, $\mathrm{PhNHNH}_{2}(30 \mu \mathrm{L}, 0.30 \mathrm{mmol})$ was used in the feed mixture. The catalyst was washed with anhydrous THF $(2 \times 5 \mathrm{~mL})$ after each run as well as after regeneration. The copper content in the crude product was determined at this stage, by ICPOES analysis of the combined eluates from each run. For purification purposes, the reaction mixture was treated with water $(20 \mathrm{~mL})$ and extracted with $\mathrm{CH}_{2} \mathrm{Cl}_{2}(2 \times 15 \mathrm{~mL})$. The combined organic layers were dried over $\mathrm{Na}_{2} \mathrm{SO}_{4}$, the volatiles were removed with a rotary evaporator and the residue was purified by flash chromatography $\left(\mathrm{SiO}_{2}, n\right.$-hexane:AcOEt $=$ $3: 1)$.

\section{Results and Discussion}

\subsection{Preparation and characterization of Cu nanoparticles supported on 3-aminopropyl} functionalized silica ( $\left.\mathrm{Cu} / \mathrm{APSiO}_{2}\right)$

$\mathrm{Cu}$ nanoparticles were prepared by MVS technique [41,42] and supported on $\mathrm{APSiO}_{2}(\mathrm{See} 2.2)$. The MVS approach allowed to deposit very small copper nanoparticles $(<5 \mathrm{~nm})$ at room temperature directly in its reduced form, so that, calcination and activation processes, which can eventually 
modify the structure of hybrid organic/inorganic support, was avoided. The choice of aminofunctionalized silica was dictated by the ability of primary alkyl amines to stabilize $\mathrm{Cu}$ nanoparticles,[43] and the strong tendency of amino functionalized silica to bind copper species.[44-48]

Transmission electron microscopy (TEM) analysis was performed in order to study the metal particle size distribution of the $\mathrm{Cu} / \mathrm{APSiO}_{2}$ samples. Copper nanoparticles turned out to be highly dispersed on the functionalized silica support and mainly present in a narrow size distribution (ranging $1.0-4.5 \mathrm{~nm}$ ), with an average diameter close to $2.5 \mathrm{~nm}$ (Figure 1). A very low amount of larger particles ranging from 10-15 $\mathrm{nm}$ in diameter, were also detected.

\section{[Figure 1, near here]}

In order to investigate the crystalline phase of starting $\mathrm{Cu}(0)$ nanoparticles obtained by MVS approach, high resolution TEM analysis were performed on the $\mathrm{Cu} / \mathrm{APSiO}_{2}$ catalyst (Figure 2).[49] Lattice planes extend to the whole particle without any stacking faults or twins, indicating their single crystalline nature. Lattice fringe analysis recorded on larger $\mathrm{Cu}$ particles $(>10 \mathrm{~nm}$, Figure 2A) exhibited spots in the FFT pattern at $2.1 \AA$ that are ascribed to the spacing of $\left(\begin{array}{lll}1 & 1 & 1\end{array}\right)$ planes of the face centered cubic (fcc) structure of metallic Cu.[50] Besides, the FFT pattern of smaller Cu nanoparticles $(<5 \mathrm{~nm})$ showed spots at $2.5 \AA$ which can be attributed to the (002) lattice spacing of $\mathrm{Cu}$ (II) oxide (Figure 2B).[51] Moreover, high resolution micrographs revealed an amorphous phase bonded to the surface of the $\mathrm{Cu}$ particles that can be due to the presence of the residual $\mathrm{APSiO}_{2}$ support. The data showed that the starting small $\mathrm{Cu}$ nanoparticles prepared in their reduced form are readily oxidised after exposition in air.

\section{[Figure 2,near here]}


Temperature Programmed Reduction (TPR) was carried out in order to get detailed information about the nature, oxidation state and reducibility of supported $\mathrm{Cu}$ catalyst.[52] The analysis consists in a reductive treatment of the catalyst under controlled temperature program and hydrogen concentration conditions. The reducibility of the supported phase strongly depends on the particles dimension, the metal oxidation state and the interaction with the matrix used as the support. The TPR of the $\mathrm{Cu} / \mathrm{APSiO}_{2}$ (Figure 3a) shows a narrow peak with a maximum at $260{ }^{\circ} \mathrm{C}$, that further confirms the presence of very uniform and small particles that easy reduce under $\mathrm{H}_{2}$ flow. The reduction temperature is in agreement with the presence of a $\mathrm{Cu}$ (II) oxide, as detected by HRTEM.[52]

\section{[Figure 3, near here]}

\subsection{Catalytic behaviour of $\mathrm{Cu} / \mathrm{APSiO}_{2}$ catalyst.}

In order to evaluate the catalytic efficiency of the supported $\mathrm{Cu}$-nanoparticles, the $\mathrm{Cu} / \mathrm{APSiO}_{2}$ system was first employed under batch reaction conditions (Table 1).

\section{[Table 1, near here]}

We were pleased to find that full conversion of 1 to the 1,2,3-triazole product $\mathbf{3}$ was achieved in $6 \mathrm{~h}$ by using $2 \mathrm{~mol}$. \% of $\mathrm{Cu}$ catalyst at room temperature. Remarkably, the reaction proceeded in the absence of any basic additive, suggesting that the primary amine groups on the support could play a duel role, as a stabilizer of $\mathrm{Cu}$ particles and as a heterogeneous base. The recovered catalyst could be reused in next 3-runs (entries 1-4, Table 1), albeit at the expense of a steady decrease of the specific activity $(\boldsymbol{S A})$. The ICP-OES analysis showed a very low amount of $\mathrm{Cu}$ species leached in the reaction mixture after each catalytic run $(<0.05 \mathrm{wt} . \%$ of the total available $\mathrm{Cu}$ content, corresponding to $0.39 \mathrm{ppm}$ in solution, entries 1-4, Table 1). Given the negligible metal leaching, oxidation of the $\mathrm{Cu}$ particles to less active $\mathrm{Cu}(\mathrm{II})$ oxide, as also evidenced 
by HRTEM and TPR analysis, was therefore considered as the most likely explanation of the loss of catalytic activity on recycling.[53]

In order to test this hypothesis, the effect of the treatment of the $\mathrm{Cu} / \mathrm{APSiO}_{2}$ catalyst with phenyl hydrazine $\left(\mathrm{PhNHNH}_{2}\right)$ was evaluated. The use of this reducing agent for selectively obtaining $\mathrm{Cu}(\mathrm{I})$ species has been reported in different reactions.[54,55] Interestingly, the $\boldsymbol{S A}$ of the $\mathrm{PhNHNH}_{2}$ treated system was almost doubled with respect to the non-activated catalyst (entry 5 vs. entry 1). TPR analysis of the $\mathrm{PhNHNH}_{2}$-treated system (Figure 3b) exhibited a shift of the reduction peak at higher temperature $\left(500{ }^{\circ} \mathrm{C}\right)$ and a shoulder at around $400{ }^{\circ} \mathrm{C}$. This change in the TPR profile confirms that a new copper phase appears after the treatment with phenyl hydrazine, which can be attributed to formation of $\mathrm{Cu}_{2} \mathrm{O}$ phase.[56] Recycling this catalyst showed similar decreasing trend of activity as that of first set of reaction; nonetheless pre-activation allowed a more effective use of supported catalyst, as higher $\boldsymbol{S A}$ values were noticed (entries 5-7 vs. entries 1-4). These results agree with the previously reported evidences on the role of $\mathrm{Cu}(\mathrm{I})$ as catalytically active species in $\mathrm{CuAAC}$ reaction. Indeed, as demonstrated by theoretical and experimental studies, the reaction mechanism involves the initial formation of $\mathrm{Cu}(\mathrm{I})$-acetylide species followed by the azide attack.[41,57-68] On the other hand, the ICP-OES data showed comparatively larger amounts of copper species released in the reaction mixture under these conditions. From the above results it was clear that $\mathrm{PhNHNH}_{2}$ is able to reduce the oxidized surface layer of copper particles and keep it in the active state, but at the same time it favors to some extent the release of the metal in the reaction mixture.[69] In order to establish the nature of the catalytic systems we monitored two test reactions performed in batch conditions with the $\mathrm{Cu} / \mathrm{APSiO}_{2}$ system untreated and pre-treated with phenyl hydrazine, respectively (Figure 2S). After conducting the reaction of phenylacetylene and benzyl azide for $2 \mathrm{~h}, 1,2,3$-triazole was produced in a yield of $35 \%$ (untreated $\mathrm{Cu} / \mathrm{APSiO}_{2}$ ) and 50 $\%$ (pre-activated $\mathrm{Cu} / \mathrm{APSiO}_{2}$ ), respectively. After that the catalysts were removed from the reaction vessels and the reaction were stirred for further $4 \mathrm{~h}$ at $25^{\circ} \mathrm{C}$ in absence of the catalysts a further conversion of less than $5 \%$ was observed. The results point out the significant heterogeneous 
contribution of the copper-based catalyst confirming that the click reaction can occur at the surface of the supported copper particle, as recently reported. [70]

The catalytic behavior of MVS-derived Cu catalyst was compared with that of previously reported $\mathrm{CuI}$ immobilized on $\mathrm{APSiO}_{2}\left(\mathrm{CuI} / \mathrm{APSiO}_{2}\right)$.[71] For this purpose $\mathrm{CuI} / \mathrm{APSiO}$ catalyst was prepared following the reported procedure.[70] Despite its easy preparation and high $S \boldsymbol{A}$ (entry 8), freshly prepared $\mathrm{CuI} / \mathrm{APSiO}_{2}$ turned out to suffer from a nearly one order of magnitude larger metal leaching ( $16 \%$ of total $\mathrm{Cu}$ content) than the MVS catalyst. Not surprisingly this led to a significant drop of catalytic activity upon recycling $\mathrm{CuI} / \mathrm{APSiO}_{2}$ (entry 9) and the inability to recover the initial performance by treatment with $\mathrm{PhNHNH}_{2}$ (entry 10).

With these promising results in hand we set out to evaluate the performance of this system under continuous flow conditions. The flow experiments were carried out using a home-made reactor packed with $\mathrm{Cu} / \mathrm{APSiO}_{2}$.[72] Given the findings in the batch runs, the catalyst was subjected to pre-activation in flow, by flushing the reactor with $\mathrm{PhNHNH}_{2}$ in THF. After brief initial optimization of flow rate, $3.75 \mathrm{mmol}$ of $\mathbf{1}$ was quantitatively converted in $5 \mathrm{~h}$ into the corresponding 1,2,3-triazole product 3 at $50 \mu \mathrm{L} \min ^{-1}$ (Table 2, entry 1 ).

\section{[Table 2, near here]}

The same flow reactor was employed next in two additional runs, without any intermediate regeneration of the catalyst (entries 2-3). Even though the recorded $\boldsymbol{S A}$ values were higher than obtained in batch (Table 2, entries 1-3 vs. Table 1, entries 5-7), a steady reduction of the conversion was noted in the course of the successive cycles. Reasoning that the activity decrease could be due to the partial oxidation of the catalyst by adventitious oxygen, TPR analysis was performed on a sample of $\mathrm{Cu} / \mathrm{APSiO}$ pre-reduced with $\mathrm{PhNHNH}_{2}$ and then exposed to air (Figure 3c).

Interestingly, the reduction profile of the air-exposed sample showed a relatively small peak with a maximum at around $250^{\circ} \mathrm{C}$, which can be traced back to the formation of the $\mathrm{CuO}$ phase. At the same time, the broad peak with shoulder at higher temperature, related to $\mathrm{Cu}_{2} \mathrm{O}$ nanoparticles, was 
still present, thus showing that only partial re-oxidation of the metal occurs when the phenylhydrazine-treated catalyst is handled in air in the dry state. Moreover, comparatively lower copper leaching was observed in continuous-flow runs than in batch. This could be explained by the reduced mechanical stress on the catalyst with respect to the stirred-flask conditions where, indeed, some grinding of silica particles by magnetic stirring was noticed. Furthermore, the catalytic activity was increased significantly if the flow reactor was regenerated before next use by flushing with $\mathrm{PhNHNH}_{2}$ (1.05 mmol, 0.21 M in THF) (entry 4) and restored completely when the reducing agent $(0.3 \mathrm{mmol}, 0.02 \mathrm{M})$ was included in the reaction feed (entry 5). With this latter modification the catalyst provided rather constant $\boldsymbol{S A}$ values in subsequent runs (entries 6 and 7) albeit, as already noticed in batch, at the expense of a some increase in the copper leaching (entries 4-7 vs. 1$3)$.

Overall the packed-bed reactor could be used effectively for seven times (entries 1-7), thus obtaining higher total productivity of catalyst $\left(\boldsymbol{P}_{\boldsymbol{n}}=727\right)[73]$ than in batch $\left(\boldsymbol{P}_{\boldsymbol{n}}=200\right.$ and 150 for the two sets of reactions, Table 1 entries 1-4 and 5-7, respectively). The amount of copper present in the combined products from all the flow reactions (53 ppm) was much less than reported for other supported Cu-systems.[31-38] Nonetheless, the leaching level in these initial experiments was still above the generally accepted $\mathrm{Cu}$ contamination in pharmaceuticals $\left(15 \mathrm{mg} \mathrm{kg}^{-1}\right)$.[35] In order to solve this problem we speculated that lowering the amount of $\mathrm{Cu}$ on $\mathrm{APSiO}_{2}$ could increase the stability of supported nanoparticles, due to the availability of comparatively more amino groups on the silica surface. Moreover, decreasing the reducing agent to the minimum amount required for keeping the catalyst in the active form could help to limit the metal dissolution.

To investigate the assumptions made above, a new batch of catalyst with lower $\mathrm{Cu}$ loading (0.55 wt.\%) was prepared and second set of flow experiments were carried out (Figure 4). Despite the comparatively lower amount of $\mathrm{Cu}$ immobilized in the device, the reactor was still able to quantitatively convert $\mathbf{1}$ to the 1,2,3-triazole product 3 at $50 \mu \mathrm{L} \mathrm{min}^{-1}$ flow-rate (run 1, Figure 2). After the initial activation, a minute amount of $\mathrm{PhNHNH}_{2}$ in the feed $(0.10 \mathrm{mmol}, 0.007 \mathrm{M})$ was 
able to keep the catalyst active for the next five-runs. Afterwards a clear decrease in activity was noticed from Run 6 to 8. Regeneration at this stage with $\mathrm{PhNHNH}_{2}$ in $\mathrm{THF}$ permitted restoring the activity of catalyst to a large extent (Runs 9 and 10), while almost the initial conversion could be attained by decreasing the flow-rate to $25 \mu \mathrm{L} / \mathrm{min}$ and adding a larger amount of reducing agent $(0.05 \mathrm{M})$ to the feed (Runs 11 and 12). Comparison of the results of Figure 4 with those obtained in the initial set of flow experiments (Table 1, entries 11-17) confirmed the anticipated advantages of using $\mathrm{Cu} / \mathrm{APSiO}_{2}(0.55 \mathrm{wt} . \%)$ instead of $\mathrm{Cu} / \mathrm{APSiO}_{2}(1.0 \mathrm{wt} . \%)$. Indeed, with proper modification of the reaction conditions the former could be used very effectively for 12 times and provided notably higher and stable $S \boldsymbol{A}$ values than the latter. As a consequence, the total productivity obtained with $\mathrm{Cu} / \mathrm{APSiO}_{2}\left(0.55\right.$ wt.\%) in flow $\left(\boldsymbol{P}_{\boldsymbol{n}}=1689\right)$ was more than two times larger of that achieved with $\mathrm{Cu} / \mathrm{APSiO}_{2}(1.0$ wt.\%) under comparable conditions (vide supra).[74] Most importantly, ICP-OES data for all the flow reactions showed now very low copper leaching in the reaction mixture $(8.1 \mathrm{ppm})[75]$, which is below the maximum allowed limit for pharmaceuticals and demonstrates the unique features of the nanostructured MVS system described in this work with respect to bulk copper catalysts and devices reported to date.[31,34-37]

\section{[Figure 4, near here]}

In order to further demonstrate the applicability of our packed-bed flow reactor, the substrate scope was briefly examined (Table 3 ). A new device containing $\mathrm{Cu} / \mathrm{APSiO}_{2}(0.55$ wt. \%) was prepared and employed to sequentially promote in continuo the CuAAC reaction of different substituted azides (1a-d) with phenylacetylene. Functional groups on the azide partner seems not to have a decisive effect on the catalytic activity, as benzyl azides with substituents at meta and para position reacted to give the corresponding 1,2,3-triazole products 3a-d in essentially quantitative yields. Remarkably, the same packed-bed reactor was used for running CuAAC reaction of the four different substrates, by intermediate washing of catalyst bed with THF and treatment with 
$\mathrm{PhNHNH}_{2}$.

[Table 3, near here]

\section{Conclusions}

New 3-aminopropylsilica supported copper catalysts have been developed, which showed remarkable activity and recyclability in continuous-flow CuAAC. With respect to other immobilized $\mathrm{Cu}$ catalysts reported to date, including nanostructured ones, [35,36,76-81] these novel systems displayed improved performances especially for what it concerns the low metal leaching and extended re-use under optimized conditions. Arguably, these unique properties can be traced back to the use of MVS-derived $\mathrm{Cu}$ nanoparticles and the possibility to prepare, by this technique, supported metal catalyst containing particles in the low nanometer range and without contamination by foreign substances. Moreover, the results confirmed that the 3-aminopropylsilica support is able to stabilize $\mathrm{Cu}$ particles without compromising the catalytic activity. As a matter of facts, the flowreactions positively compete with the batch ones, thus affording larger quantity of product (i.e. greater $\boldsymbol{P}_{\boldsymbol{n}}$ of catalyst) and simplified separation procedures. Careful tailoring of reaction conditions and $\mathrm{Cu}$ loading on $\mathrm{APSiO}_{2}$ allowed exploiting the supported catalyst more effectively and for longer time and also to diminish the metal leaching in the reaction medium. In this context the feasibility of extending the catalyst' life-time by reduction in continuo of phenylhydrazine was also demonstrated for the first time. The versatility of the flow-system was also proven by sequentially converting different substrates to 1,2,3-triazole products with the same column.

\section{Acknowledgement}

This work was supported by the Italian Ministry of University and Scientific Research (MIUR) under the FIRB 2010 program (RBFR10BF5V). 
Figure 1. Transmission electron microscopy (TEM) image of a freshly prepared $\mathrm{Cu} / \mathrm{APSiO}_{2}$ sample.
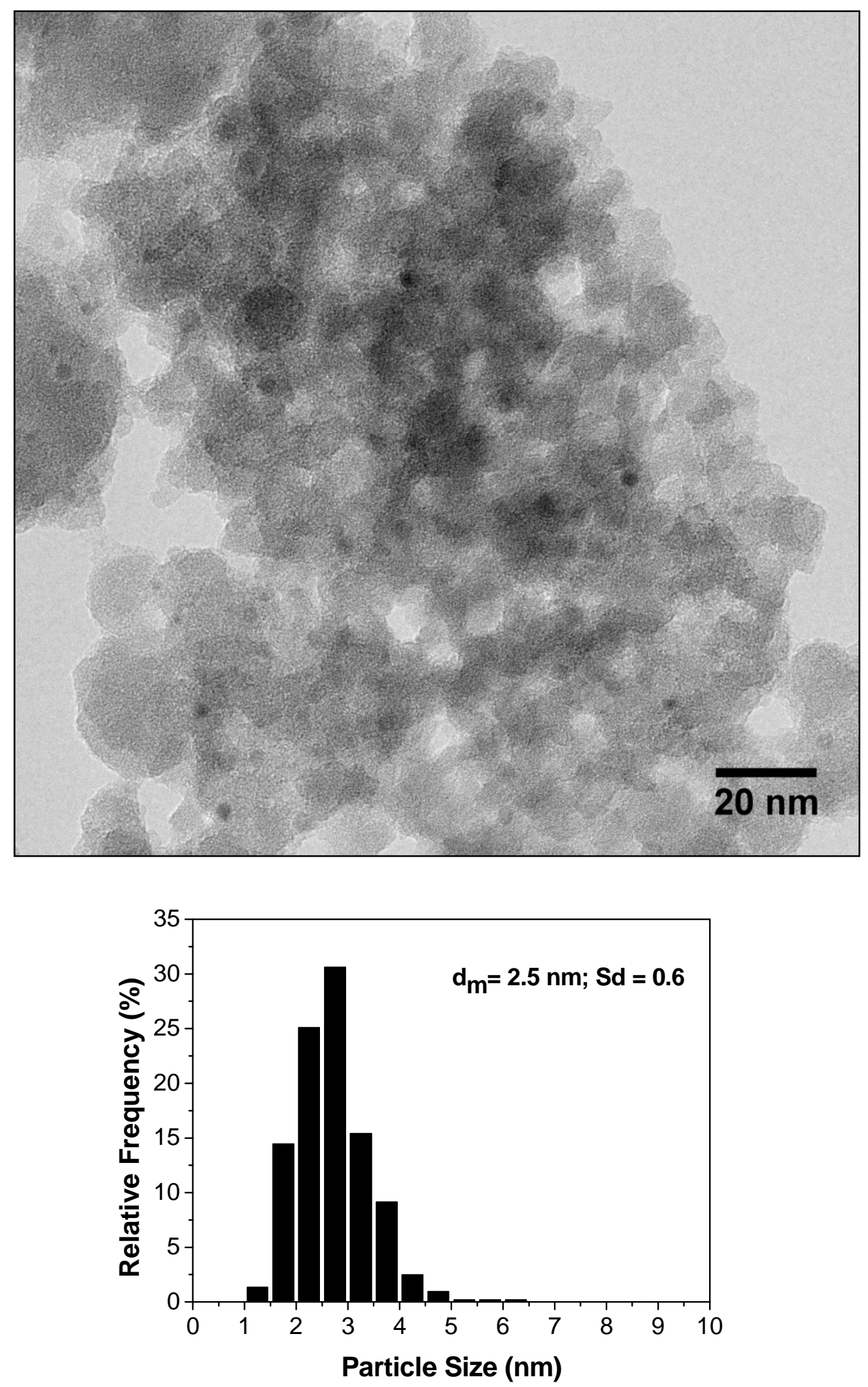

14 
Figure 2. HRTEM micrograph of $\mathrm{Cu}$ nanoparticles and inverted FFT pattern taken from $\mathrm{A}$ and $\mathrm{B}$ squared areas, respectively.

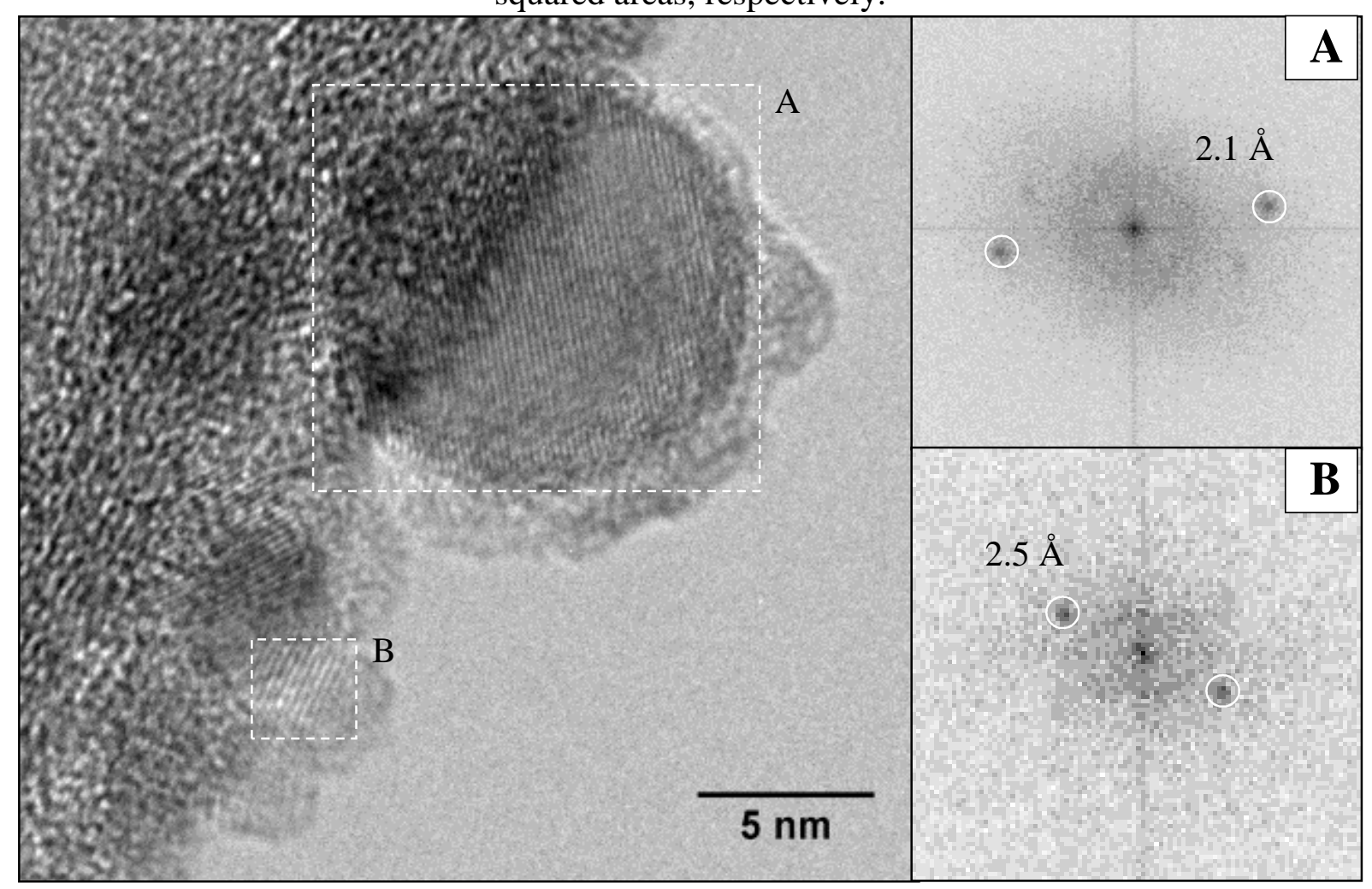


Figure 3. TPR profiles of $\mathrm{Cu} / \mathrm{AP}-\mathrm{SiO}_{2}$ : freshly prepared (blue line), reduced with phenylhydrazine (red line) and air-exposed after the reduction (green line).

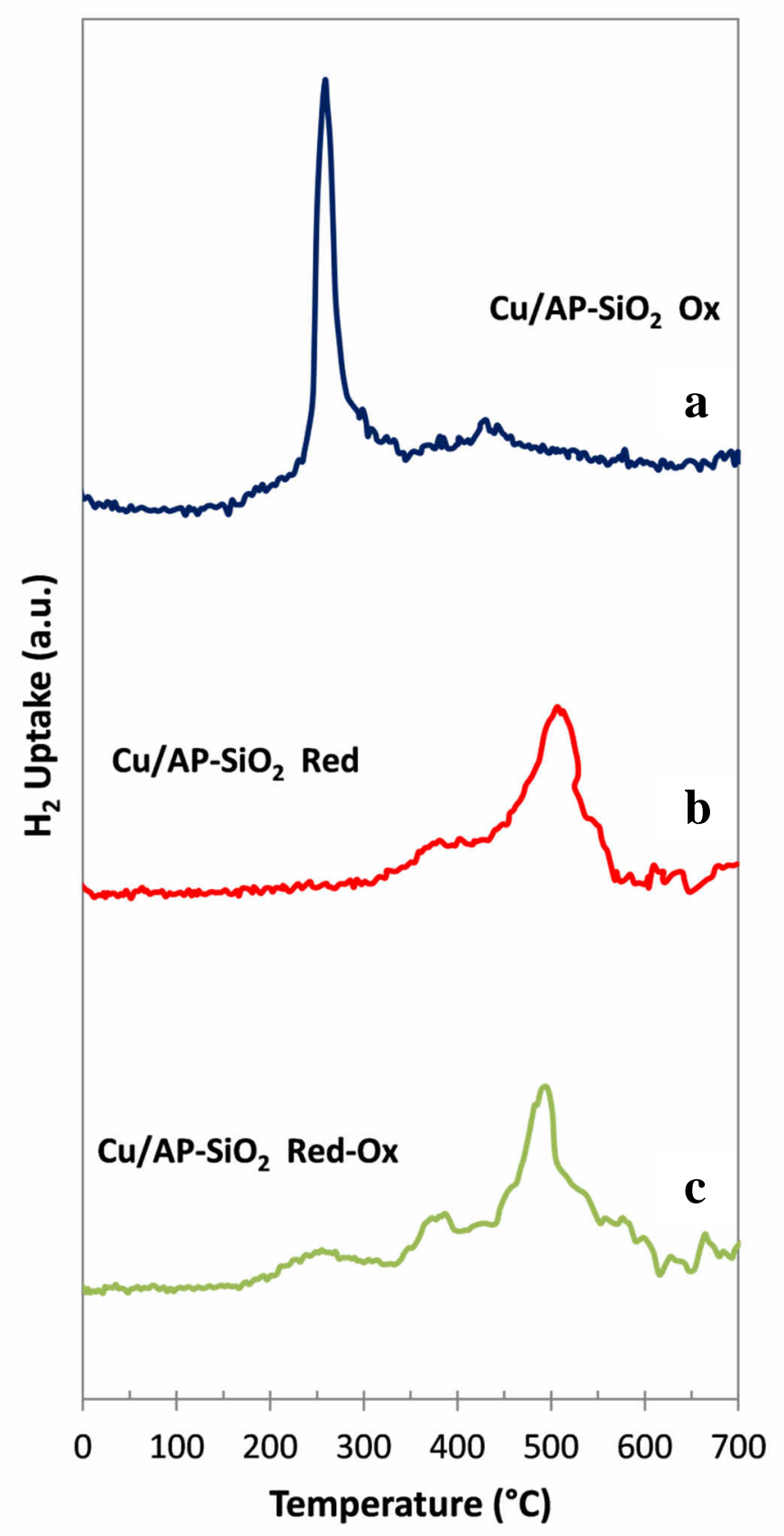


Figure 4. Continuous-flow click reaction between phenyl acetylene and benzyl azide using $\mathrm{Cu} / \mathrm{APSiO}_{2}(0.55$ wt. \%).

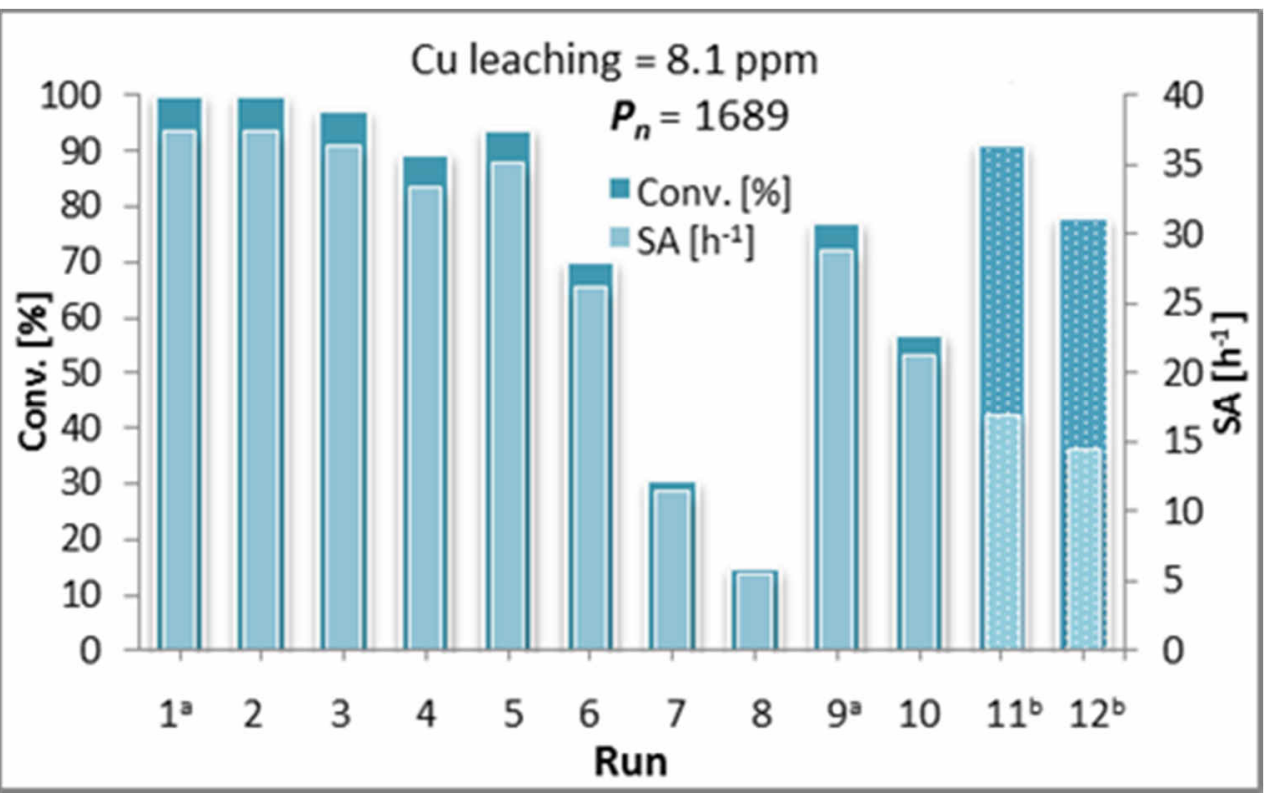

Reaction conditions for each run: $\mathrm{Cu} / \mathrm{APSiO}_{2} 0.55 \mathrm{wt} . \%$ (230 mg, $0.02 \mathrm{mmol}$ of $\mathrm{Cu}$ ), benzylazide (3.75 mmol), phenylacetylene ( $4.5 \mathrm{mmol})$, THF $(15 \mathrm{~mL}), \mathrm{PhNHNH}_{2}(9.8 \mu \mathrm{L}, 0.1 \mathrm{mmol})$, flow-rate $=50 \mu \mathrm{L} / \mathrm{min}, \mathrm{T}=25^{\circ} \mathrm{C}$. a) Pre-activated with $\mathrm{PhNHNH}_{2}(69 \mu \mathrm{L}, 0.7 \mathrm{mmol}$ in $5 \mathrm{~mL} \mathrm{THF}) ;$ b) 25 $\mu \mathrm{L} / \mathrm{min}$ flow-rate, pre-activated and reaction run in presence of $\mathrm{PhNHNH}_{2}(69 \mu \mathrm{L}, 0.7 \mathrm{mmol})$ added to the feed. 
Table 1. $\mathrm{CuAAC}$ reaction in batch reaction conditions using $\mathrm{Cu} / \mathrm{APSiO}_{2}$ catalyst

Table 2. CuAAC reaction in continuous-flow reaction conditions using $\mathrm{Cu} / \mathrm{APSiO} \mathrm{O}_{2}$ catalyst

Table 3. Substrate scope in continuous-flow $\mathrm{CuAAC}$ reaction using $\mathrm{Cu} / \mathrm{APSiO}_{2}$ catalyst 
Table 1.

\begin{tabular}{|c|c|c|c|c|c|}
\hline Entry & Catalyst & Time $[\mathrm{h}]$ & Conversion $[\%]^{[\mathrm{a}]}$ & Specific Activity (SA) $\left[h^{-1}\right]^{[b]}$ & Leaching $[\%]^{[\mathrm{c}]}$ \\
\hline 1 & $\begin{array}{c}\mathrm{Cu} / \mathrm{APSiO}_{2} \\
1.0 \text { wt. } \%\end{array}$ & $\begin{array}{l}2 \\
6\end{array}$ & $\begin{array}{c}38 \\
100\end{array}$ & 9.5 & 0.005 \\
\hline 2 & $\begin{array}{l}\text { Re-cycled } \\
\text { from run } 1\end{array}$ & $\begin{array}{l}2 \\
6\end{array}$ & $\begin{array}{c}21 \\
100\end{array}$ & 5.25 & $<$ limit \\
\hline 3 & $\begin{array}{l}\text { Re-cycled } \\
\text { from run } 2\end{array}$ & $\begin{array}{c}2 \\
24\end{array}$ & $\begin{array}{c}9 \\
99\end{array}$ & 2.25 & 0.05 \\
\hline 4 & $\begin{array}{l}\text { Re-cycled } \\
\text { from run } 3\end{array}$ & 24 & 79 & 1 & 0.06 \\
\hline $5^{[\mathrm{d}]}$ & $\begin{array}{c}\mathrm{Cu} / \mathrm{APSiO}_{2} \\
1.0 \text { wt. } \%\end{array}$ & $\begin{array}{l}2 \\
4\end{array}$ & $\begin{array}{c}70 \\
100\end{array}$ & 17.5 & 1.9 \\
\hline 6 & $\begin{array}{l}\text { Re-cycled } \\
\text { from run } 5\end{array}$ & $\begin{array}{l}2 \\
6\end{array}$ & $\begin{array}{c}50 \\
100\end{array}$ & 12.5 & 1.5 \\
\hline 7 & $\begin{array}{l}\text { Re-cycled } \\
\text { from run } 6\end{array}$ & $\begin{array}{c}2 \\
4 \\
12\end{array}$ & $\begin{array}{c}15 \\
30 \\
100\end{array}$ & 3.75 & 1.3 \\
\hline 8 & $\begin{array}{c}\mathrm{CuI} / \mathrm{APSiO}_{2} \\
1.0 \text { wt. } \%\end{array}$ & $\begin{array}{l}2 \\
6\end{array}$ & $\begin{array}{l}71 \\
93\end{array}$ & 17.7 & 16 \\
\hline 9 & $\begin{array}{l}\text { Re-cycled } \\
\text { from run } 8\end{array}$ & $\begin{array}{l}2 \\
6\end{array}$ & $\begin{array}{l}22 \\
76\end{array}$ & 5.5 & 14 \\
\hline $10^{[\mathrm{d}]}$ & $\begin{array}{l}\text { Re-cycled } \\
\text { from run } 9\end{array}$ & $\begin{array}{l}2 \\
6\end{array}$ & $\begin{array}{l}29 \\
66\end{array}$ & 7.3 & 5 \\
\hline
\end{tabular}

Reaction conditions: $\mathrm{Cu} / \mathrm{APSiO}_{2} 1.0$ wt. $\%(65 \mathrm{mg}, 0.01 \mathrm{mmol}$ of $\mathrm{Cu})$ benzyl azide $(0.5 \mathrm{mmol}, 1$ equiv.), phenyl acetylene ( $0.6 \mathrm{mmol}, 1.2$ equiv.), THF $(2 \mathrm{~mL}), \mathrm{T}=25^{\circ} \mathrm{C}$. [a] determined by ${ }^{1} \mathrm{H} \mathrm{NMR}$; [b] Calculated as moles of benzyl azide converted/moles of $\mathrm{Cu}$ per hour (calculated after $2 \mathrm{~h}$ ); [c] determined by ICP-OES, on the basis of the total available copper; [d] catalyst pre-activated using $\mathrm{PhNHNH}_{2}(34 \mu \mathrm{L}, 0.35 \mathrm{mmol})$ in THF (5 mL). 


\section{Table 2.}

\begin{tabular}{|c|c|c|c|}
\hline Entry & Conversion $[\%]^{[\mathbf{a}]}$ & Specific Activity $(\mathbf{S A})\left[\mathbf{h}^{-\mathbf{1}}\right]^{[\mathbf{b}]}$ & ${\text { Leaching }[\%]^{[\mathbf{c}]}}$ \\
\hline $1^{[\mathrm{d}]}$ & 99 & 24.7 & $<0.01$ \\
\hline 2 & 73 & 18.3 & 0.2 \\
\hline 3 & 50 & 12.5 & 0.3 \\
\hline $4^{[\mathrm{d}]}$ & 85 & 21.2 & 2.7 \\
\hline $5^{[\mathrm{e}]}$ & 100 & 25.0 & 5.2 \\
\hline $6^{[\mathrm{e}]}$ & 94 & 23.5 & 4.8 \\
\hline $7^{[\mathrm{e}]}$ & 79 & 19.7 & 1.2 \\
\hline
\end{tabular}

Reaction conditions: $\mathrm{Cu} / \mathrm{APSiO}_{2} 1.0 \mathrm{wt} \%$ (190 mg, $0.03 \mathrm{mmol}$ of $\mathrm{Cu}$ ), benzyl azide (3.75 mmol, 1 equiv.), phenyl acetylene ( $4.5 \mathrm{mmol}, 1.2$ equiv.), THF $(15 \mathrm{~mL})$, flow rate $=50 \mu \mathrm{L} / \mathrm{min}, \mathrm{T}=25^{\circ} \mathrm{C}, \mathrm{t}=5 \mathrm{~h}$. [a] determined by ${ }^{1} \mathrm{H}$ NMR; [b] Calculated as moles of benzyl azide converted/moles of $\mathrm{Cu}$ per hour (calculated after $2 \mathrm{~h}$ ); [c] determined by ICPOES, on the basis of the total available copper; [d] catalyst pre-activated using $\mathrm{PhNHNH}_{2}(103 \mu \mathrm{L}, 1.05 \mathrm{mmol})$ in THF (5 mL); [e] $\mathrm{PhNHNH}_{2}(30 \mu \mathrm{L}, 0.30 \mathrm{mmol})$ was added to the reaction feed. 
Table 3.

Substrate 1

Reaction conditions: $\mathrm{Cu} / \mathrm{APSiO}_{2}, 0.55$ wt. $\%$ (223 mg, $0.019 \mathrm{mmol}$ of $\mathrm{Cu}$ ), benzyl azide (2.5 mmol, 1 equiv.), phenyl acetylene (3.0 mmol, 1.2 equiv.), THF $(10 \mathrm{~mL}), \mathrm{PhNHNH}_{2}(9 \mu \mathrm{L}, 0.095 \mathrm{mmol})$, flow-rate $=50 \mu \mathrm{L} / \mathrm{min}, \mathrm{T}=25^{\circ} \mathrm{C}$. Before each run the catalyst was activated with $\mathrm{PhNHNH}_{2}(66 \mu \mathrm{L}, 0.67 \mathrm{mmol}$ in $5 \mathrm{~mL} \mathrm{THF})$. [a] Calculated by ${ }^{1} \mathrm{H}$ NMR. 


\section{References}

[1] V.V. Rostovtsev, L.G. Green, V.V. Fokin, K.B. Sharpless, Angew. Chem. Int. Ed., 41 (2002) 2596-2599.

[2] R. Huisgen, G. Szeimies, L. Moebius, Chem. Ber., 100 (1967) 2494-2507.

[3] C.W. Tornoe, C. Christensen, M. Meldal, J. Org. Chem. 67 (2002) 3057-3064.

[4] D.D. Diaz, S. Punna, P. Holzer, A.K. McPherson, K.B. Sharpless, V.V. Fokin, M.G. Finn, J. Polym. Sci., Part A:

Polym. Chem., 42 (2004) 4392-4403.

[5] V. Aucagne, K.D. Haenni, D.A. Leigh, P.J. Lusby, D.B. Walker, J. Am. Chem. Soc., 128 (2006) 2186-2187.

[6] J.-F. Lutz, Angew. Chem., Int. Ed., 46 (2007) 1018-1025.

[7] V. Aucagne, J. Berna, J.D. Crowley, S.M. Goldup, K.D. Haenni, D.A. Leigh, P.J. Lusby, V.E. Ronaldson, A.M.Z.

Slawin, A. Viterisi, D.B. Walker, J. Am. Chem. Soc., 129 (2007) 11950-11963.

[8] I. Aprahamian, W.R. Dichtel, T. Ikeda, J.R. Heath, J.F. Stoddart, Org. Lett., 9 (2007) 1287-1290.

[9] S. Yigit, R. Sanyal, A. Sanyal, Chem. - Asian J., 6 (2011) 2648-2659.

[10] A. Gregory, M.H. Stenzel, Prog. Polym. Sci., 37 (2012) 38-105.

[11] A. Kumar, P. Kumar, H. Joshi, Int. J. Curr. Res. Rev., 4 (2012) 21-31.

[12] P. Thirumurugan, D. Matosiuk, K. Jozwiak, Chem. Rev., 113 (2013) 4905-4979.

[13] M. Meldal, C.W. Tornøe, Chem. Rev.108 (2008) 2952-3015.

[14] T. Jin, M. Yan, Y. Yamamoto, ChemCatChem, 4 (2012) 1217-1229.

[15] Y.M.A. Yamada, S.M. Sarkar, Y. Uozumi, J. Am. Chem. Soc., 134 (2012) 9285-9290.

[16] Q. Sun, Z. Lv, Y. Du, Q. Wu, L. Wang, L. Zhu, X. Meng, W. Chen, F.-S. Xiao, Chem.-An Asian J., 8 (2013) 28222827.

[17] X. Xiong, L. Cai, Catal. Sci. Technol., 3 (2013) 1301-1307.

[18] R.B.N. Baig, R.S. Varma, Green Chem., 15 (2013) 1839-1843.

[19] J.-M. Collinson, J.D.E.T. Wilton-Ely, S. Diez-Gonzalez, Chem. Commun., 49 (2013) 11358-11360.

[20] M. Nasr-Esfahani, I. Mohammadpoor-Baltork, A.R. Khosropour, M. Moghadam, V. Mirkhani, S. Tangestaninejad, H. Amiri Rudbari, J. Org. Chem., 79 (2014) 1437-1443.

[21] X. Xiong, L. Cai, Y. Jiang, Q. Han, ACS Sustainable Chem. Eng. 2 (2014) 765-771.

[22] X. Xiong, H. Chen, Z. Tang, Y. Jiang, RSC Advances, 4 (2014) 9830-9837.

[23] A. Sarkar, T. Mukherjee, S. Kapoor, J. Phys. Chem. C, 112 (2008) 3334-3340.

[24] D. Raut, K. Wankhede, V. Vaidya, S. Bhilare, N. Darwatkar, A. Deorukhkar, G. Trivedi, M. Salunkhe, Catal. Commun., 10 (2009) 1240-1243.

[25] F. Alonso, Y. Moglie, G. Radivoy, M. Yus, Eur. J. Org. Chem., 10 (2010) 1875-1884

[26] F. Alonso, Y. Moglie, G. Radivoy, M. Yus, Adv. Synth. Catal., 352 (2010) 3208-3214.

[27] R. Hudson, C.-J. Li, A. Moores, Green Chem., 14 (2012) 622-624F F. Alonso, Y. Moglie, G. Radivoy, M. Yus, Adv. Synth. Catal., 352 (2010) 3208-3214.

[28] B.S.P. Anil Kumar, K. Harsha Vardhan Reddy, B. Madhav, K. Ramesh, Y.V.D. Nageswar, Tetrahedron Lett., 53 (2012) 4595-4599.

[29] H. Woo, H. Kang, A. Kim, S. Jang, J.C. Park, S. Park, B.-S. Kim, H. Song, K.H. Park, Molecules, 17 (2012)

$13235-13252$.

[30] G.A. Rance, W.A. Solomonsz, A.N. Khlobystov, 49 (2013) 1067-1069.

[31] A.R. Bogdan, N.W. Sach, Adv. Synth. Catal., 351 (2009) 849-854.

[32] A.R. Bogdan, K. James, Org. Lett., 13 (2011) 4060-4063.

[33] L. Kupracz, J. Hartwig, J. Wegner, S. Ceylan, A. Kirschning, Beilstein J. Org. Chem., 7 (2011) 1441-1448.

[34] S.B. Otvos, A. Georgiades, I.M. Mandity, L. Kiss, F. Fulop, Beilstein J Org Chem, 9 (2013) 1508-1516.

[35] M. Fuchs, W. Goessler, C. Pilger, C.O. Kappe, Adv. Synth. Catal., 352 (2010) 323-328

[36] C.D. Smith, I.R. Baxendale, S. Lanners, J.J. Hayward, S.C. Smith, S.V. Ley, Org. Biomol. Chem., 5 (2007) 15591561.

[37] S.B. Ötvös, I.M. Mándity, L. Kiss, F. Fülöp, Chem. - Asian J., 8 (2013) 800-808.

[38] A.R. Bogdan, K. James, Chem. Eur. J., 16 (2010) 14506-14512.

[39] G. Vitulli, C. Evangelisti, A.M. Caporusso, P. Pertici, N. Panziera, S. Bertozzi, P. Salvadori in: B. Corain, G. Schmid, N. Toshima (Eds.), Metal nanoclusters in catalysis and materials science: the issue of size-control, Elsevier, Amsterdam, 2008, Chapter 32.

[40] J.S. Bradley in: G. Schmid (Eds.), Clusters and Colloids. From Theory to Applications, VCH: Weinheim, 1994, p.459.

[41] A.A. Ponce, K.J. Klabunde, J. Mol. Cat. A: Chemical, 225 (2005) 1-6.

[42] C. Evangelisti, G. Vitulli, E. Schiavi, M. Vitulli, S. Bertozzi, P. Salvadori, L. Bertinetti, G. Martra, Catal. Lett., 116 (2007) 57-62.

[43] G. Molteni, C.L. Bianchi, G. Marinoni, N. Santo, A. Ponti, New J. Chem., 30 (2006) 1137-1139.

[44] M.V. Lombardo, M. Videla, A. Calvo, F.G. Requejo, G.J.A.A. Soler-Illia, J. Hazard. Mater., 223-224 (2012) 53-

62.

[45] J. Aguado, J.M. Arsuaga, A. Arencibia, M. Lindo, V. Gascon, J. Hazard. Mater., 163 (2009) 213-221.

[46] F. Hoffmann, M. Cornelius, J. Morell, M. Froeba, Angew. Chem., Int. Ed., 45 (2006) 3216-3251. 
[47] H. Yoshitake, J. Mater. Chem., 20 (2010) 4537-4550.

[48] Z. Wu, D. Zhao, Chem. Commun. , 47 (2011) 3332-3338.

[49] The sample of was finely crushed and sonicated for $8 \mathrm{~h}$ : this treatment allowed the detachment of $\mathrm{Cu}$ particle from the support, favoring easy detection of their structural features by HRTEM.

[50] C. Wu, B.P. Mosher, T. Zeng, J. Nanopart. Res., 8 (2006) 965-969.

[51] J. Urban, H. Sack-Kongehl, K. Weiss, Catal. Lett., 49 (1997) 101-108.

[52] F. Zaccheria, N. Scotti, M. Marelli, R. Psaro, N. Ravasio, Dalt. Trans., 42 (2013) 1319-1328.

[53] V.V. Fokin, K. Matyjaszewski, CuAAC: The Quintessential Click Reaction, in: Organic Chemistry -

Breakthroughs and Perspectives, Wiley-VCH Verlag GmbH \& Co. KGaA, 2012, pp. 247-277.

[54] S.K. Ginotra, V.K. Singh, Tetrahedron, 62 (2006) 3573-3581.

[55] T. Komori, N. Satoh, S. Yokoshima, T. Fukuyama, Synlett, 2011 (2011) 1859-1862.

[56] S. Song, R. Rao, H. Yang, A. Zhang, J. Phys. Chem. C, 114 (2010) 13998-14003.

[57] V.V. Rostovtsev, L.G. Green, V.V. Fokin, K.B. Sharpless, Angew. Chem., Int. Ed., 41 (2002) 2596-2599.

[58] C.W. Tornoe, C. Christensen, M. Meldal, J. Org. Chem., 67 (2002) 3057-3064

[59] G.C. Tron, T. Pirali, R.A. Billington, P.L. Canonico, G. Sorba, A.A. Genazzani, Med. Res. Rev., 28 (2008) $278-$

308.

[60] M. Meldal, C.W. Tornoe, Chem. Rev., 108 (2008) 2952-3015.

[61] F. Amblard, J.H. Cho, R.F. Schinazi, Chem. Rev., 109 (2009) 4207-4220.

[62] L. Duran Pachon, J.H. van Maarseveen, G. Rothenberg, Adv. Synth. Catal., 347 (2005) 811-815

[63] B.H. Lipshutz, B.R. Taft, Angew. Chem., Int. Ed., 45 (2006) 8235-8238.

[64] S. Chassaing, M. Kumarraja, A.S.S. Sido, P. Pale, J. Sommer, Org. Lett., 9 (2007) 883-886.

[65] S. Chassaing, A.S.S. Sido, A. Alix, M. Kumarraja, P. Pale, J. Sommer, Chem. - Eur. J., 14 (2008) 6713-6721.

[66] T. Miao, L. Wang, Synthesis, (2008) 363-368.

[67] H. Sharghi, R. Khalifeh, M.M. Doroodmand, Adv. Synth. Catal., 351 (2009) 207-218.

[68] B.S. Lee, M. Yi, S.Y. Chu, J.Y. Lee, H.R. Kwon, K.R. Lee, D. Kang, W.S. Kim, H.B. Lim, J. Lee, H.-J. Youn,

D.Y. Chi, N.H. Hur, Chem. Commun. (Cambridge, U. K.), 46 (2010) 3935-3937.

[69] However, as experimentally evaluated (see ESI), the amount of $\mathrm{Cu}$ leached was not able to catalyse the reaction in the homogeneous phase

[70] M.R. Decan, S. Impellizzeri, M.L. Marin, J.C. Scaiano, Natur. Comm. 5 (2014) 1-8.

[71] T. Miao, L. Wang, Synthesis, (2008) 363-368.

[72] For a detailed description of packed-bed column preparation, see the supporting information.

[73] $\boldsymbol{P}_{\mathrm{n}}=$ mols product obtained up to the $n$-th run over mols of catalyst initially used.

[74] Remarkably, these results approach the productivity of some of the most effective homogeneous catalytic systems reported to date, e.g. $\boldsymbol{P}=1960$ provided by $(\mathrm{BimC} 4 \mathrm{~A})_{3} / \mathrm{CuSO}_{4} / \mathrm{ascorb}$ ate. [See: a) V.O. Rodionov, S.I. Presolski, S. Gardinier, Y.-H. Lim , M.G. Finn, J. Am. Chem. Soc. (2007), 129, 12696; b) R. Berg, B.F. Straub, Beilstein J. Org. Chem. (2013), 9, 2715]

[75] The $\mathrm{Cu}$ loading of the used catalyst measured by ICP-OES analysis was $0.51 \mathrm{wt} . \%$ confirming a very low $\mathrm{Cu}$ leaching (ca. $7 \%$ ) as resulted from the leaching tests performed in the reaction mixture.

[76] T.R. Chan, V.V. Fokin, QSAR Comb. Sci., 26 (2007) 1274-1279.

[77] K. Namitharan, M. Kumarraja, K. Pitchumani, Chem. - Eur. J., 15 (2009) 2755-2758.

[78] S. Roy, T. Chatterjee, M. Pramanik, A.S. Roy, A. Bhaumik, S.M. Islam, J. Mol. Catal. A: Chem., 386 (2014) 7885.

[79] C.S. Radatz, L.d.A. Soares, E.R. Vieira, D. Alves, D. Russowsky, P.H. Schneider, New J. Chem., 38 (2014) 14101417.

[80] D. Wang, L. Etienne, M. Echeverria, S. Moya, D. Astruc, Chem. - Eur. J., 20 (2014) 4047-4054.

[81] L. Huang, W. Liu, J. Wu, Y. Fu, K. Wang, C. Huo, Z. Du, Tetrahedron Lett., 55 (2014) 2312-2316. 